\title{
An Anatomical Feasibility Study Using CTA Reconstruction for Modified Percutaneous Lumbar Vertebroplasty
}

Jun Guo ( $\nabla$ gzd713@163.com )

Orthopaedics Department $₫$ First Affiliated Hospital of Tsinghua University $\varangle$ Beijing China

Xu Jianbiao

School of Clinical Medicine, Tsinghua University 『Beijing \China

Fan Shali

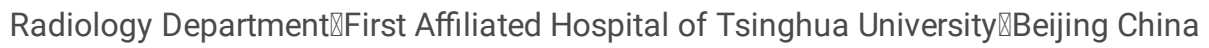

$\mathrm{Ni}$ Yu

Orthopaedics Department囚First Affiliated Hospital of Tsinghua University囚Beijing China

James Reeves Mbori Ngwayi

School of Clinical Medicine, Tsinghua University $₫$ Beijing $\llbracket C h i n a$

Edward Porter

School of Clinical Medicine, Tsinghua University \Beijing \China

\section{Research Article}

Keywords: osteoporotic vertebral compression fracture, percutaneous vertebroplasty, lumbar arteries

Posted Date: January 24th, 2022

DOI: https://doi.org/10.21203/rs.3.rs-1176338/v1

License: () (1) This work is licensed under a Creative Commons Attribution 4.0 International License. Read Full License 


\section{Abstract}

Study Design. Observational anatomical imaging study

Objective. To investigate the anatomical feasibility of percutaneous vertebroplasty for lumbar osteoporotic vertebral compression fractures via a unilateral Extrapedicular approach.

Summary of Background Data. Lumbar vertebroplasty via several different types of extrapedicular approach has been reported with acceptable clinical results yet the anatomical basis for its safety is not fully explored. Injury to the lumbar arteries (LAs) is one of the most important potential complications. However, anatomical research on the course and variability of this structure is lacking.

Methods. A total of 300 LAs of 30 patients with non-spinal disorders were retrospectively analyzed by computed tomographic angiography (CTA). The lateral aspect of the vertebral body was divided into 9 zones of approximately equal area. The anatomy and orientation of LAs were analyzed in detail.

Results. LAs were most commonly found in the middle third of the body (zones 4,5 , and 6 ); the upper $1 / 3$ of the vertebral body had LAs distributed only anteriorly and laterally (zones 1 and 2). No arteries were observed in the postero-superior segment (zone 3 ). From L1 to L3 an arched pattern predominated. At L4 an inferior oblique pattern (antero-superior to postero-inferior) predominated. Limited CTA visualization at L4 and particularly L5 as well as greater anatomical variation means that there is more uncertainty at these levels.

Conclusion. From L1 to L3, the posterior superior segment (zone 1) of the vertebral body appears to be a safe area with low risk of arterial injury. This has relevance for design of a safe lumbar vertebral extrapedicular approach.

\section{Introduction}

Percutaneous vertebroplasty (PVP) is a minimally invasive technique for the treatment of osteoporotic vertebral compression fractures (OVCF) [1, 2]. The procedure can quickly relieve pain, promote early mobilisation and reduce related complications caused by bed rest. Currently, the transpedicular approach is the most widely used surgical method for lumbar OVCF[3]. However, due to the restricted pedicle orientation, unilateral puncture has the disadvantage of uneven and usually ipsilateral distribution of bone cement, especially where the pedicle is narrow and following anatomical distortion due to fracture[4]. Uneven distribution of bone cement will affect the mechanical balance of the spine and the clinical efficacy of surgery[5].

Previous studies have shown that extrapedicular PVP puncture has the advantages of more uniform distribution of bone cement and reduced fluoroscopic exposure[6-10]. However, reports of damage to the lumbar artery during extrapedicular PVP puncture exist[11, 12]. Data on standard and anomalous arterial course relevant to this technique are not available, in part due to variation in the mode of extrapedicular approach described by different authors. The point of bone contact and cortical entry point on the lateral wall of the pedicle or vertebral body have not been described in detail. Integral to the safety of this approach is an understanding of the anatomical relationship between the lateral wall of the vertebral body and the lumbar arteries (LAs).

The purpose of this study, therefore, was to analyze the course of the lumbar segmental artery adjacent to the lateral wall of the vertebral body together with its variation, and to consider its clinical significance.

\section{Materials And Methods}

\section{Patients and General Information}

The imaging data of 30 adult patients with intra-abdominal or urological disorders undergoing total abdominal CTA (computerized tomography angiography) examination in our medical institution performed between 1 October 2019 and 1 December 2020. Inclusion criteria were as follows: (1) age was between 20-80 years old; (2) CTA reconstruction segment was T12-L5. Exclusion criteria: (1) patients with scoliosis, spinal tumor, and other serious lumbar diseases; (2) patients with previous lumbar surgery; (3) patients who met the inclusion criteria but had poor reconstruction image quality. This project was approved by the research ethics committee of our institution(Ethics approval NO: 2020-33-R01).

A Philips Brillance 64 spiral CT scanner(Amsterdam, Netherlands) was used to image the abdomen as described above. Images included the entire lower thoracic and lumbar spine, and associated arteries including LAs. Contrast agent (lomeron, 350ml/ml) was 
injected into the median cubital vein at a rate of $5 \mathrm{ml} / \mathrm{s}$ and a dose of $80 \mathrm{ml}$. The scanning time was triggered at radiodensity threshold 150 Hounsfield Units. The thickness of CTA was $5 \mathrm{~mm}$, the thickness of reconstruction was $1 \mathrm{~mm}$, and the interval was $1 \mathrm{~mm}$. The anatomical structure of each LA was reconstructed and evaluated on the Philips extended brilliance workspace(FUJIFILM Synapse 3D, Tokyo, Japan). First, a single researcher (XJB) extracted both left lateral and right lateral 2D images of the region of interest. Upon the image a grid was superimposed which divided, the vertebral body into nine zones; in the horizontal plane the middle (para-pedicular) third was defined as the zone between horizontal lines parallel to the upper and lower margins of the pedicle. the upper and lower thirds (supra-pedicular and infrapedicular respectively) were defined as the portion of the body above and below this section. The image was divided further by two verical lines which produced three vertical segments of equal width from anterior to posterior. Second, the course of the LA across the surface of different segments was evaluated (Fig. 1). The evaluation was conducted by two doctors (XJB and FSL) independently, with the assistance of researcher GJ in case of disagreement. Finally, the segmental level, number, orientation, and branches of each LA was documented, and if not seen, its absence. According to their course, LAs were divided into five types: A. horizontal type; B. inferior oblique type (course from superanterior to posteroinferior), C. superior oblique type (course from inferoanterior to superoposterior), ; D. arched type; E. mixed type (Fig. 2).

\section{Statistical Analysis}

SPSS 23.0(IBM, USA) was used for statistical analysis. Intraclass correlation coefficient (ICC) was calculated for data generated by each observer. In general, ICC values range from 0 to 1 . If the ICC value is less than 0.4 , the repeatability of the diagnostic test is poor; If ICC value is greater than 0.75 , the repeatability of diagnostic test is better. Overall summary statistics were calculated in terms of frequencies and percentages for categorical variables and means \pm SD for continuous variables. In this study, the $t$ test was used for continuous data and chi square test for categorical data, with $\mathrm{P}<0.05$ as the significance standard.

\section{Results}

\section{Demographics.}

Imaging data from 30 patients were collated; 18 males (age range 22-69 years, mean age 55.3 \pm 25.7 years);12 females (age range 48-72 years, mean age $57.2 \pm 21.4$ years). There was no significant difference in age between men and women $(P>0.05)$.

\section{Lumbar artery distribution.}

Distribution of arteries within zones are recorded in Table 1. Interrater agreement was excellent; ICC $=0.91$. Typical examples of CTA and distribution zones of lumbar artery are shown in Figure 3 and 4. For the upper three lumbar segments(L1-L3), zones LAs were found to cross mainly the para-pedicular and infrapedicular thirds of the vertebral body. No vessels were found to cross zone 3 (postero-superior aspect). The distribution of LAs in L4 and L5 were different, with the LA tending to run from antero-superior to postero-inferior (inferior oblique pattern - see below) (Table 1).

Table 1

Distribution of lumbar arteries within zones at each lumbar level L1-L5.

\begin{tabular}{|llllllllll|}
\hline Lumbar level & \multicolumn{2}{l}{ Supra-pedicular 1/3 } & \multicolumn{3}{c}{ Para-pedicular 1/3 } & \multicolumn{3}{l|}{ Infrapedicular 1/3 } \\
\cline { 2 - 10 } & $\begin{array}{l}\text { Zone 1 } \\
\text { (Anterior) }\end{array}$ & $\begin{array}{l}\text { Zone 2 } \\
\text { (Middle) }\end{array}$ & $\begin{array}{l}\text { Zone 3 } \\
\text { (Posterior) }\end{array}$ & $\begin{array}{l}\text { Zone 4 } \\
\text { (Anterior) }\end{array}$ & $\begin{array}{l}\text { Zone 5 } \\
\text { (Middle) }\end{array}$ & $\begin{array}{l}\text { Zone 6 } \\
\text { (Posterior) }\end{array}$ & $\begin{array}{l}\text { Zone 7 } \\
\text { (Anterior) }\end{array}$ & $\begin{array}{l}\text { Zone 8 } \\
\text { (Middle) }\end{array}$ & $\begin{array}{l}\text { Zone 9 } \\
\text { (Posterior) }\end{array}$ \\
\hline L1 & 0 & 0 & 0 & 25 & 51 & 50 & 48 & 6 & 12 \\
\hline L2 & 0 & 0 & 0 & 15 & 43 & 45 & 50 & 16 & 19 \\
\hline L3 & 8 & 2 & 0 & 35 & 54 & 35 & 33 & 5 & 28 \\
\hline L4 & 36 & 10 & 0 & 17 & 41 & 22 & 3 & 1 & 36 \\
\hline L5 & 1 & 1 & 0 & 1 & 1 & 0 & 3 & 2 & 3 \\
\hline
\end{tabular}

Twenty four spines had bilateral missing lumbar arteries on CTA. These were all at the L5 level where the absence rate was $80 \%$ ); Ten spines had a unilateral missing lumbar artery ( two at L1,two at L4 and 6 at L5. Where absent at one level, eight lumbar arteries from L3 
to L5 demonstrated segmental branches above or below the missing vessel. Vessel absence or segmental braching were evenly distributed on left and right sides. No vessel was observed in Zone 3 (postero-superior zone). The distribution of rare LA variations is shown in Figure 5.

\section{Vascular classification}

Among the 300 lumbar segments, we found 237 identifiable vascular patterns; 105 vessels were type D, 47 vessels were type A, 45 vessels were type $B, 26$ vessesl were type $C$ and 14 cases were type E. From $L 1$ to $L 3$ type $D$ (arch) predominated), however at $L 4$ type $B$ (inferior oblique) predominated (Table 2).

Table 2

Distribution of lumbar artery vascualr patterns.

\begin{tabular}{|c|c|c|c|c|c|}
\hline $\mathrm{N}$ & $\begin{array}{l}\text { Type A } \\
\text { (horizontal) }\end{array}$ & $\begin{array}{l}\text { Type B } \\
\text { (inferior oblique) }\end{array}$ & $\begin{array}{l}\text { Type C } \\
\text { (superior oblique) }\end{array}$ & $\begin{array}{l}\text { Type D } \\
\text { (arch) }\end{array}$ & $\begin{array}{l}\text { Type } \mathrm{E} \\
\text { (mixed) }\end{array}$ \\
\hline \multicolumn{6}{|l|}{ L1 } \\
\hline Left & 5 & 0 & 3 & 18 & 2 \\
\hline Right & 7 & 0 & 11 & 12 & 0 \\
\hline Total & 12 & 0 & 14 & 30 & 2 \\
\hline \multicolumn{6}{|l|}{ L2 } \\
\hline Left & 9 & 0 & 1 & 19 & 0 \\
\hline Right & 10 & 1 & 9 & 10 & 0 \\
\hline Total & 19 & 1 & 10 & 29 & 0 \\
\hline \multicolumn{6}{|l|}{ L3 } \\
\hline Left & 3 & 5 & 0 & 20 & 2 \\
\hline Right & 8 & 2 & 2 & 15 & 3 \\
\hline Total & 11 & 7 & 2 & 35 & 5 \\
\hline \multicolumn{6}{|l|}{ L4 } \\
\hline Left & 1 & 18 & 0 & 6 & 2 \\
\hline Right & 2 & 15 & 0 & 5 & 5 \\
\hline Total & 3 & 33 & 0 & 11 & 7 \\
\hline \multicolumn{6}{|l|}{ L5 } \\
\hline Left & 1 & 3 & 0 & 0 & 0 \\
\hline Right & 1 & 1 & 0 & 0 & 0 \\
\hline Total & 2 & 4 & 0 & 0 & 0 \\
\hline Total & 47 & 45 & 26 & 105 & 14 \\
\hline
\end{tabular}

\section{Discussion}

To date, several series of patients with thoraco-lumbar extrapedicular approach have been reported without major complication[7-9, 12, 13]. Injury to the lumbar artery is one of the main concerns in extrapedicular puncture and has been reported in the literature[11]. However this should be considered in the context of similar reports in transpedicular vertebroplasty. Five cases of lumbar artery injury caused by PVP or PKP have been reported in the previous literature. Among these, four cases were punctured through the transpedicular approach and 1 case was punctured through an extrapedicular approach (Table 3). Previous studies on the anatomy of the lumbar 
artery have focused on the soft-tissue distribution of arteries around the spinal nerve with the aim of avoiding neurological symptoms during endoscopic surgery[14]. It is generally considered that surgery adjacent to the lumbar intervertebral disc will avoid injury to the lumbar artery in oblique lumbar interbody fusion (OLIF) or extreme lateral interbody fusion (XLIF)[15, 16]. To our knowledge, there are no studies on the safe area of extrapedicular PVP puncture, especially the distribution of blood vessels around the pedicle. This study is the first report to study the distribution of the lumbar artery on the lateral side of the vertebral body.

Table 3

Reported cases of Lumbar artery injury caused by PVP (PKP)

\begin{tabular}{|c|c|c|c|c|c|c|c|c|}
\hline Case & Author & Disease & Operation & $\begin{array}{l}\text { Damage } \\
\text { location }\end{array}$ & $\begin{array}{l}\text { Early } \\
\text { symptoms }\end{array}$ & Diagnosis & Treatment & Outcome \\
\hline Case1 & $\begin{array}{l}\text { Biafora,S.J.,et } \\
\text { al[17] }\end{array}$ & OVCF(L5) & $\begin{array}{l}\text { PKP(Transpedicular } \\
\text { approach) }\end{array}$ & $\begin{array}{l}\text { Right } \\
\text { L4LA }\end{array}$ & $\begin{array}{l}\text { Incisional } \\
\text { bleeding }\end{array}$ & Angiography & TAE & Cured \\
\hline Case2 & $\begin{array}{l}\text { Heo, D.H.et } \\
\text { al[11] }\end{array}$ & oVCF(L2) & $\begin{array}{l}\text { PVP(Extrapedicular } \\
\text { approach) }\end{array}$ & $\begin{array}{l}\text { Left L2 } \\
\text { LA }\end{array}$ & $\begin{array}{l}\text { Backache, } \\
\text { left lower } \\
\text { limb neural } \\
\text { symptom, } \\
\text { acute } \\
\text { hypotension }\end{array}$ & $\begin{array}{l}\text { Enhanced } \\
\text { MRI }\end{array}$ & TAE & Cured \\
\hline Case3 & Puri et al[18] & OVCF(L3) & $\begin{array}{l}\text { PVP(Transpedicular } \\
\text { approach) }\end{array}$ & $\begin{array}{l}\text { Left } \\
\text { L3LA }\end{array}$ & $\begin{array}{l}\text { Backache, } \\
\text { psoas } \\
\text { hematoma }\end{array}$ & CTA & TAE & Cured \\
\hline Case4 & Puri et al[18] & OVCF(L3) & $\begin{array}{l}\text { PVP(Transpedicular } \\
\text { approach) }\end{array}$ & $\begin{array}{l}\text { Right } \\
\text { L3LA }\end{array}$ & Anemia & CTA & TAE & Cured \\
\hline Case5 & $\begin{array}{l}\text { Giordano et } \\
\text { al[19]. }\end{array}$ & $\begin{array}{l}\text { Vertebral } \\
\text { Metastases }\end{array}$ & $\begin{array}{l}\text { PVP(Transpedicular } \\
\text { approach) }\end{array}$ & $\begin{array}{l}\text { Left } \\
\text { L2LA }\end{array}$ & $\begin{array}{l}\text { Left lower } \\
\text { abdominal } \\
\text { pain }\end{array}$ & $\begin{array}{l}\text { Contrast- } \\
\text { enhanced } \\
\text { CT }\end{array}$ & TAE & Cured \\
\hline
\end{tabular}

A thorough understanding of the spinal arteries before percutaneous endoscopic lumbar discectomy is a necessary stage to reduce the risk of intraoperative bleeding. In the present study, the distribution of the lumbar artery has the following characteristics: 1 . the distribution of LAs in different vertebral segments is slightly different. L1, L2, and L3 were mainly distributed in the middle (parapedicular) and lower (infra-perdicular) thirds; L4 was mainly distributed in the middle and upper (supra-pedicular) thirds, with a predominant inferior oblique pattern. Previous studies have shown that the LA branch angles are acute $\left(<90^{\complement}\right)$ at L1-L3 and blunt (>90) at L4-L5[20]. Tezuka, F., et al. analysed 323 CTA images and found that from L1 to L4, each segmental artery was identified bilaterally in more than $90 \%$ of subjects, but was identified in less than $10 \%$ of patients at L5[16]; a phenomenon which we also identified.

Zone 3 of L1-3 (postero-superior corner of the vertebral body) is a safe area for extrapedicular puncture. However, this study also showed that an oblique lumbar artery on the side of L4 and L5 vertebrae (figure 5F). Previous studies have also confirmed that the L4 and 5 have high variation rates [16]. At this levelwe suggest that CTA of the lumbar artery could be performed to confirm the course of lumbar artery or transpedicular puncture should be used.

This study has the following limitations: (1) CTA can only display the main trunk of the lumbar artery with a diameter of more than 1 $\mathrm{mm}$, and is usually unable to identify more distal branches; (2) Due to the small sample size of this study, confidence is limited about minor anatomical variations; (3) Measurement errors are possible with two observers, however images were evaluated by a professional imaging physician and an orthopedic specialist, with excellent inter-rater agreement. (4) The course of lumbar veins and venous plexus anatomy was not studied in this research. We could not find any report on venous injury during vertebroplasty. The possible reason is hematoma formed after venous injury is difficult to detect due to the absence of obvious clinical symptoms.

\section{Conclusion}

This study suggests that the posterior superior angle of L1-3 vertebral bodies (zone 3) is usually a safe area with minimal arterial risk. On this basis, we consider an osseous puncture point within this area, however its clinical safety should be further confirmed in surgical practice. Due to the existence of branches of the lumbar artery at L4 and L5 levels, we advocate caution for this method here. 


\section{Abbreviations}

LAs: lumbar arteries; CTA: computed tomographic angiography; PKP: Percutaneous vertebroplasty; OVCF: osteoporotic vertebral compression fractures; OLIF: lumbar artery in oblique lumbar interbody fusion; XLIF: extreme lateral interbody fusion; ICC: Intraclass correlation coefficient ; PVP: Percutaneous Vertebroplasty; TAE: Transarterial Embolization.

\section{Declarations}

\section{- Ethics approval and consent to participate}

Informed consent was obtained in writing from all the individual participants included in the study. This project was approved by the research ethics committee of The First Affiliated Hospital of Tsinghua University, Beijing, China (Ethics approval NO: 2020-33-R01).

\section{- Consent for publication}

Informed consent was obtained in writing from all the individual participants included in the study.

\section{- Availability of data and materials}

The datasets used and/or analysed during the current study are available from the corresponding author on reasonable request.

\section{- Competing interests}

No conflict of interest exits in the submission of this manuscript, and manuscript is approved by all authors for publication. I would like to declare on behalf of my co-authors that the work described was original research that has not been published previously, and not under consideration for publication elsewhere, in whole or in part.

\section{- Funding}

No Funding.

\section{- Authors' contributions}

XJB, FSL and GJ made substantial contributions to conception and design of the study. XJB, FSL and NY made analysis and interpretation of data. James Reeves mbori ngwayi and DE Porter are responsible for language polishing. XJB, FSL, GJ, DE Porter have been involved in the drafting of the manuscript and have given final approval of the version to be published.

\section{- Acknowledgements}

The authors would like to thank JianQiang Liu (Radiology Department, First affiliated Hospital of Tsinghua University) for partial image processing. The authors would like to give special thanks to all of the staff and patients, who provided support to the general practices involved in the study.

\section{References}

1. Kushchayev SV, Wiener PC, Teytelboym OM, et al, Percutaneous Vertebroplasty: A History of Procedure, Technology, Culture, Specialty, and Economics[J]. Neuroimaging Clin N Am, 2019. 29(4): 481-494.

2. Hide IG, Gangi A, Percutaneous vertebroplasty: history, technique and current perspectives[J]. Clin Radiol, 2004. 59(6): 461-467.

3. Wang SMD, Wang QMD, Kang JMD, et al, An Imaging Anatomical Study on Percutaneous Kyphoplasty for Lumbar Via a Unilateral Transverse Process-Pedicle Approach[J]. Spine April, 2014. 39(9): 701-706.

4. Chen B, Li Y, Xie D, et al, Comparison of unipedicular and bipedicular kyphoplasty on the stiffness and biomechanical balance of compression fractured vertebrae[J]. Eur Spine J, 2011. 20(8): 1272-1280.

5. Chevalier Y, Pahr D, Charlebois M, et al, Cement distribution, volume, and compliance in vertebroplasty: some answers from an anatomy-based nonlinear finite element study[J]. Spine (Phila Pa 1976), 2008. 33(16): 1722-1730.

Page 6/9 
6. Ringer AJ, Bhamidipaty SV, Percutaneous access to the vertebral bodies: a video and fluoroscopic overview of access techniques for trans, extra-, and infrapedicular approaches[J]. World Neurosurg, 2013. 80(3-4): 428-435.

7. Ge J, Cheng X, Li P, et al, The Clinical Effect of Kyphoplasty Using the Extrapedicular Approach in the Treatment of Thoracic Osteoporotic Vertebral Compression Fracture[J]. World Neurosurg, 2019. 131: e284-e289.

8. Piao M, Darwono AB, Zhu K, et al, Extrapendicular Approach of Unilateral Percutaneous Vesselplasty for the Treatment of Kummell Disease[J]. Int J Spine Surg, 2019. 13(2): 199-204.

9. Wang YF, Shen J, Li SY, et al, Kambin triangle approach in percutaneous vertebroplasty for the treatment of osteoporotic vertebral compression fractures[J]. Medicine (Baltimore), 2019. 98(44).

10. Wang LM, Liu FY, Lu K, et al, Modified extrapedicular kyphoplasty for the treatment of lumbar compression fracture: Case report and technical note[J]. Medicine (Baltimore), 2020. 99(6).

11. Heo DH, Cho YJ, Segmental Artery Injury Following Percutaneous Vertebroplasty Using Extrapedicular Approach[J]. J Korean Neurosurg Soc, 2011. 49(2): 131-133.

12. Cho SM, Nam YS, Cho BM, et al, Unilateral extrapedicular vertebroplasty and kyphoplasty in lumbar compression fractures: technique, anatomy and preliminary results[J]. J Korean Neurosurg Soc, 2011. 49(5): 273-277.

13. Mishra PK, Dwivedi R, Dhillon CS, Osteoporotic Vertebral Compression Fracture and Single Balloon Extrapedicular Kyphoplasty: Findings and Technical Considerations[J]. Bull Emerg Trauma, 2020. 8(1): 34-40.

14. Zhao QP, Zhong EP, Shi BP, et al, Clinical Anatomy and Possible Clinical Significance of the Postcentral Branches of Spinal Arteries in the L1-L5 Levels[J]. Clinical Spine Surgery October, 2020. 33(8): 328-332.

15. Nojiri H, Miyagawa K, Banno S, et al, Lumbar artery branches coursing vertically over the intervertebral discs of the lower lumbar spine: an anatomic study[J]. European Spine Journal, 2016. 25(12): 4195-4198.

16. Tezuka F, Sakai T, Nishisho T, et al, Variations in arterial supply to the lower lumbar spine[J]. Eur Spine J, 2016. 25(12): 4181-4187.

17. Biafora SJ, Mardjetko SM, Butler JP, et al, Arterial injury following percutaneous vertebral augmentation: a case report[J]. Spine, 2006. 31(3): 84-87.

18. Puri AS, Colen RR, Reddy AS, et al, Lumbar artery pseudoaneurysm after percutaneous vertebroplasty: a unique vascular complication[J]. J Neurosurg Spine, 2011. 14(2): 296-299.

19. Giordano AV, Arrigoni F, Bruno F, et al, Interventional Radiology Management of a Ruptured Lumbar Artery Pseudoaneurysm after Cryoablation and Vertebroplasty of a Lumbar Metastasis[J]. CardioVascular and Interventional Radiology, 2017. 40(5): 776-779.

20. Wu T, Xiao L, Liu C, et al, Anatomical Study of the Lumbar Segmental Arteries in Relation to the Oblique Lateral Interbody Fusion Approach[J]. World Neurosurgery, 2020. 138: e778-e786.

\section{Figures}

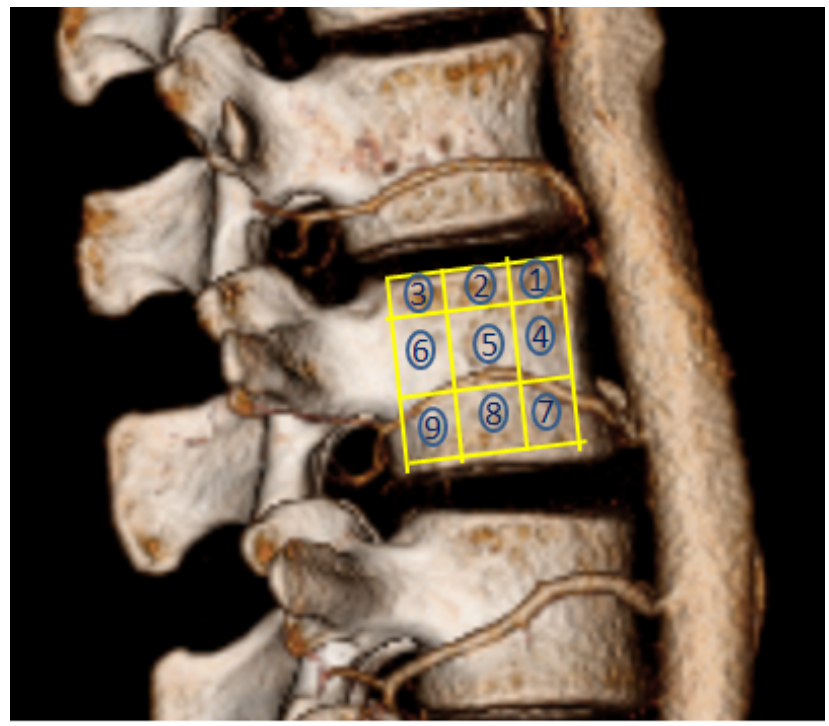

Figure 1 


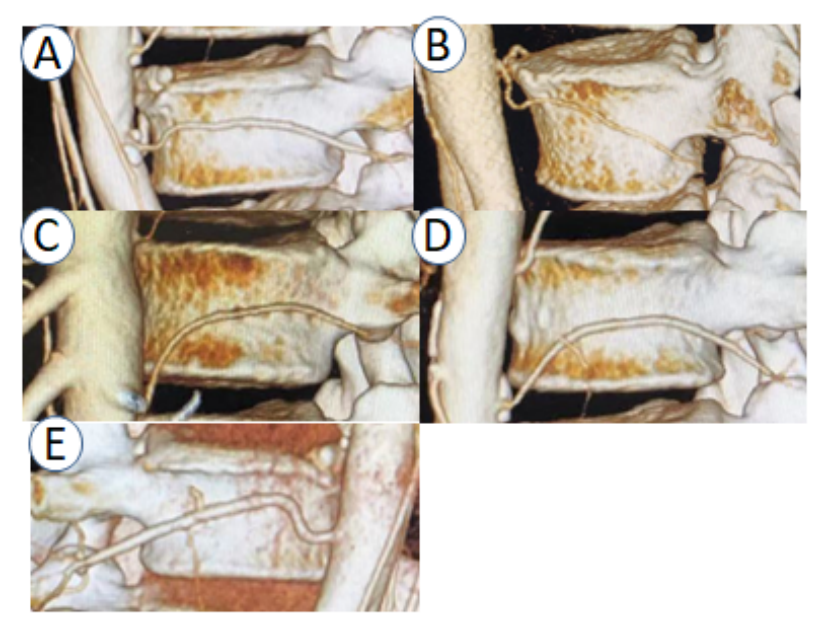

Figure 2

Classification of lumbar artery (LA) types. According to their course, LAs were divided into five types: A horizontal type; B inferior oblique type; C superior oblique type; D arch type; E mixed type.

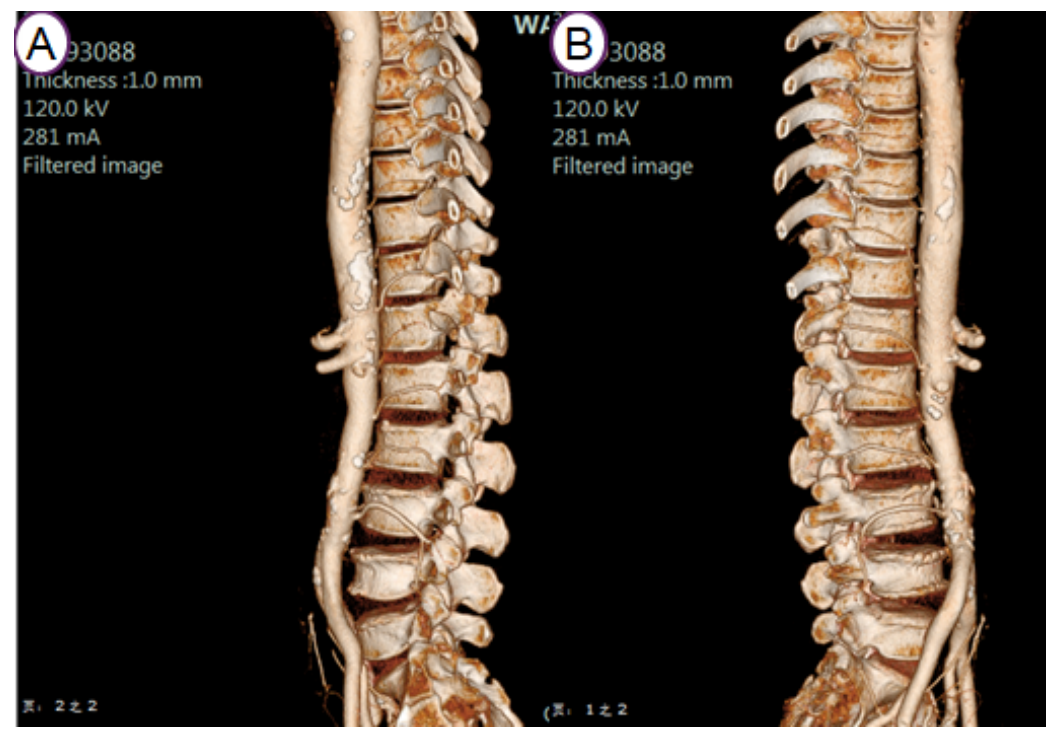

\section{Figure 3}

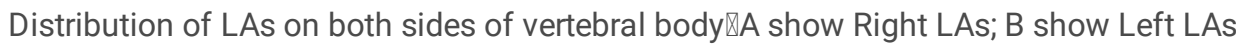

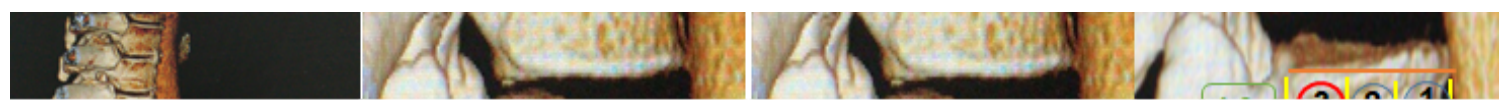




\section{Figure 4}

Distribution of LA in different lumbar segments (L1-L4) (L1: 4,5,6; L2: 4,5,6; L3: 4,5,6,7; L4: 1,4,5,6,9; L5 deletion)

\section{Figure 5}

Rare distribution variations of lumbar artery Fig. A: left L5 artery (Zone 1,5,9); B: Absence of L1 artery; C: L4 artery straddles L5 superior articular process obliquely; D: Right L5 artery exists and straddles S1 vertebral body obliquely (Zone 1,5,9); E: Left L5 artery exists and straddles S1 vertebral body obliquely (Zone 4,7); F: L3 artery straddles L4 vertebral body obliquely 